\title{
Abstract \\ A High-Resolution Fully Inkjet Printed Resonant Mass Sensor ${ }^{\dagger}$
}

\author{
Bruno Andò *(D, Salvatore Baglio, Ruben Crispino $(\mathbb{1})$ and Vincenzo Marletta
}

check for

updates

Citation: Andò, B.; Baglio, S.; Crispino, R.; Marletta, V. A High-Resolution Fully Inkjet Printed Resonant Mass Sensor. Eng. Proc. 2021, 6, 9. https://doi.org/ 10.3390/I3S2021Dresden-10087

Academic Editors: Gianaurelio Cuniberti and Larysa Baraban

Published: 17 May 2021

Publisher's Note: MDPI stays neutral with regard to jurisdictional claims in published maps and institutional affiliations.

Copyright: (c) 2021 by the authors. Licensee MDPI, Basel, Switzerland. This article is an open access article distributed under the terms and conditions of the Creative Commons Attribution (CC BY) license (https:// creativecommons.org/licenses/by/ $4.0 /)$.
Deptement of Electric Electronic and Information Engineering (DIEEI), University of Catania, 95125 Catania, Italy; salvatore.baglio@unict.it (S.B.); ruben.crispino@unict.it (R.C.); vincenzo.marletta@dieei.unict.it (V.M.)

* Correspondence: bruno.ando@unict.it

+ Presented at the 8th International Symposium on Sensor Science, 17-28 May 2021; Available online: https://i3s2021dresden.sciforum.net/.

\begin{abstract}
The rapid prototyping of low-cost sensors is assuming strategic importance in several application fields. In this paper, a fully inkjet printed mass sensor is proposed. The device consists of a poly-ethylene terephthalate (PET) cantilever beam, which is driven to its resonant mode by an electromagnetic actuation mechanism, implemented through the interaction between a current impulse flowing through a planar coil (inkjet printed on the PET beam), and a permanent magnet, facing the actuation coil. Target masses are positioned close to the beam end. The sensing methodology, based on the relationship between the beam first natural frequency and the target mass, is implemented through a strain gauge (inkjet printed across the fixed end of the cantilever). The resonant operating mode of the sensor confers intrinsic robustness against instabilities of the strain sensor structure (e.g., the residual stress of the cantilever beam), the target mass material and the magnet-coil distance. The latter indeed changes as a function of the target mass values. The friction-less actuation mode is another shortcoming of the sensor, as well as the low-cost feature arising from the adopted technology. As far as we know, the solution proposed is the first example of a low-cost fully printed mass sensor. The operating range of the device is $0-0.36 \mathrm{~g}$ while its resolution is in the order of $1.0 \mathrm{mg}$, thus addressing crucial application fields. A $Q$ factor around 35 has been estimated, which confirms the suitable performances of the sensor in term of selectivity and resolution.
\end{abstract}

Keywords: mass sensor; inkjet printing; flexible; resonant operation

Supplementary Materials: The following are available online at https:/ /www.mdpi.com/article/10 .3390/I3S2021Dresden-10087/s1, Poster S1: i3s_S6_10087_A_High_Resolution_Fully_Inkjet_slides.

Author Contributions: Conceptualization, B.A. and S.B.; methodology, B.A. and R.C.; validation, V.M.; investigation, V.M. and R.C.; writing-original draft preparation, B.A. and V.M.; writingreview and editing, B.A. and V.M. All authors have read and agreed to the published version of the manuscript.

Conflicts of Interest: The authors declare no conflict of interest. 